
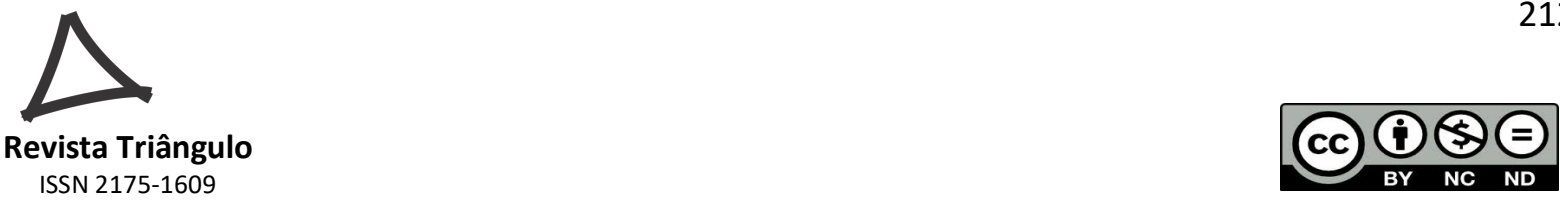

\title{
A ARGUMENTAÇÃO NO ENSINO DE CIÊNCIAS: UM DELINEAMENTO DAS PRODUÇÕES ACADÊMICAS BRASILEIRAS NO PERÍODO DE 2010 A 2018
}

\author{
THE ARGUMENTATION IN SCIENCE TEACHING: A DESIGN OF THE \\ BRAZILIAN ACADEMIC PRODUCTIONS IN THE PERIOD FROM 2010 TO 2018 \\ LA ARGUMENTACIÓN EN LA ENSEÑANZA DE CIENCIAS: UN DELINEAMIENTO \\ DE LAS PRODUCCIONES ACADÉMICAS BRASILEÑAS EN EL PERÍODO DE 2010 A \\ 2018
}

Agnaldo Ronie Pezarini

E-mail: rpezarini@gmail.com

Doutorando em Ensino de Ciências e Matemática - Universidade Cruzeiro do Sul

Maria Delourdes Maciel

E-mail: delourdes.maciel@gmail.com

Universidade Cruzeiro do Sul

\begin{abstract}
RESUMO
Partindo do viés de que uma educação científica se constitui a partir da competência argumentativa, temos por objetivo apresentar neste artigo a produção acadêmica brasileira de três Lócus distintos, sendo eles: Seis periódicos nacionais, o Encontro Nacional de Pesquisa em Educação em Ciências (ENPEC) e o Banco Digital de Teses e Dissertações (BDTD). Enaltecemos que ao construir este estado da arte selecionamos pesquisas sobre a temática Argumentação no Ensino de Ciências e elencamos para análise os seguintes aspectos: Instituição de origem; Disciplina de trabalho da argumentação; Foco temático; Nível de escolaridade; Objetivo e ou pretensão da pesquisa; Elemento de construção da argumentação ou ferramenta de análise da argumentação; Autoria acadêmica e Resultados obtidos. Como resultado encontramos a temática Argumentação no Ensino de Ciências e suas produções acadêmicas sendo produzidas praticamente em todo o país, o foco temático tem ênfase em estratégias promotoras da argumentação científica e sociocientífica, o Padrão de Toulmin é o elemento de construção e ou ferramenta analítica da argumentação mais utilizado, mesmo havendo outros teóricos das ações argumentativas e que o viés de práticas investigativas contribuam positivamente para a construção da argumentação.
\end{abstract}

PALAVRAS-CHAVE: Argumentação. Ensino de Ciências. Mapeamento da Argumentação. Toulmin.

\section{ABSTRACT}

Starting off, with the bias of a scientific education that constitutes from the argumentation competence, our objective is to present in this article the Brazilian academic production of three distinct loci, them being: Six periodic national ones, the National Meeting of Research in Education in Sciences (ENPEC) and the Digital Bank of Thesis and Dissertations (BDTD). We exalt that, when constructing this state of the art, we select the research on the thematic Argument in teaching of the Sciences and, we ask for analysis for the following aspects: Institution of origin; discipline of work of the argument; Thematic focus; Level of schooling; Objective and or pretension of the research; Element of construction of the argument or tool of analysis of the argument; Academic authorship and the obtained Results. As result we all find the thematic Argument in teaching of the Sciences and its academic productions being practically produced all around the country, the thematic focus has emphasis in promotional strategies of the scientific and sociocientific argument, the Standard of Toulmin is the element of construction and or analytical tool of the most used argument, even though they have other theoreticians of the argumentative actions and that the bias of practical investigative, positively contributes for the construction of arguments.

KEYWORDS: Argumentation. Science teaching. Mapping of the Argumentation. Toulmin. 


\section{RESUMEN}

Partiendo de las propuestas de que una educación cientifica se constituye a partir de la competencia argumentativa, tenemos por objetivo presentar em este articulo la producción academica Brasilera de tres Bases distintas ,siendo ellas: Seis revistas nacioalesel Encuentro Nacional de investigación em educación em Ciencias (ENPEC) y el Banco Digital de Tesis y disertaciones (BDTD). Enaltecemos que al construir este estado de arte selecionamos investigaciones sobre la temática Argumentativa em la enseñanza de Ciencias y catalogamos para analisis de los siguientes aspectos: Institución de origen; Diciplina de trabajo de la argumentación; Punto temático; Grado de escolaridade; Objetivo y pretención de la investigación; ; elementos de construcción de la argumentación, herramientas de analisis de la argumentación ;Autoria academica y resultados obtenidos. Como resultados encontramos la temática y argumentación em la enseñanza de ciências y sus prducciones acadêmicas siendo producidas practicamentes em todo el pais, el punto y temático tiene enfasis em estratégias que promueven la argumentación cientifica y sociocientífica, al Padron de Toulmin y el elemento de construcción y herramienta analítica de argumentación mas utilizado aunque haya otros teóricos de las acciónes argumentativas y que la propuestas de practicas investigativas contribuyen positivamente para la construcción de la argumetación.

PALABRAS-CLAVE: Argumentación. Enseñanza de Ciencias. Mapeo de la Argumentación. Toulmin.

\section{INTRODUÇÃO}

É recorrente nas últimas décadas encontrarmos no cenário da produção científica e acadêmica trabalhos e pesquisas sobre a Argumentação no ensino de Ciências. Mas do que se trata tais buscas? A resposta a essa indagação se faz necessária para o discernimento entre a argumentação comum para a língua materna e a praticada no contexto do ensino de ciências. De antemão, à luz de Kuhn (1993) enaltecemos a existência da dela, que em suas palavras nos revela que:

É no argumento que nós podemos encontrar a maneira mais significativa na qual o pensamento e o raciocínio figuram na vida de pessoas comuns. Pensamento como argumento está implicado em todas as crenças que as pessoas têm, nos julgamentos que elas fazem e nas conclusões que elas tiram (KUHN, 1993, p. 322)

Portanto, é uma ação que está para além de um simples ato classificado como simplório e banal, ele se faz essencial para o processo de formação cidadã, bem como é um elemento intrínseco ao processo de construção da alfabetização científica. Corrobora com essa afirmação o que nos diz (FERRAZ \& SASSERON, 2017)

Devido à natureza social da atividade científica, a argumentação emerge como uma prática epistêmica central em seu desenvolvimento, pois envolve ações, como a elaboração de explicações sobre distintos fenômenos e, além disso, por meio da justificação de alegações e da concatenação de evidências teóricas e/ou empíricas novas ideias são colocadas em debate para validação e aceitação pela comunidade (FERRAZ \& SASSERON, 2017, p. 2) 

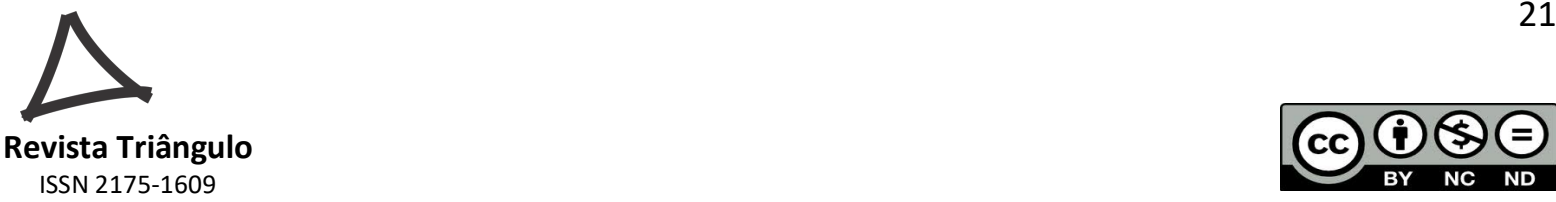

Logo, o viés e/ou propósito da Argumentação no Ensino de Ciências está na promoção de uma educação e/ou aprendizagem de qualidade, que de fato contribua para a formação cidadã ao subsidiar ao processo elementos que propiciem a construção do conhecimento científico e da alfabetização científica. Ou seja, neste contexto, cabe a afirmação de que a argumentação e/ou as estratégias de sua construção são meios para a alfabetização científica.

A argumentação no contexto do ensino de ciências parte de pressupostos específicos, de modo que, tal especificidade caracteriza e diferencia o processo da científica para a clássica e, para tanto, faz uso de modelos e/ou padrões que os definem, como nos diz (SASSERON \& CARVALHO, 2011)

\footnotetext{
Parte da ideia de que uma asserção feita defende uma alegação. Os fatos que apoiam esta alegação são os dados (D) e são os fundamentos com os quais se constrói o suporte à conclusão $(\mathrm{C})$ que se busca apresentar. [...] a conclusão, no padrão de Toulmin, representa o final do argumento: não só porque assim aparece na frase, mas especialmente porque se caracteriza por ser o resultado da alegação proposta. (SASSERON \& CARVALHO, 2011, p. 100)
}

Diante do exposto pelas pesquisadoras, fica evidenciado que o Padrão de Stephen Toulmin (1958/2006) é um modelo coerente e aplicável para as práticas que envolvem a construção e ou análise da argumentação e, não se classifica como um processo de simples ação, ele requer a relação entre os seus elementos constituintes bem como a garantia, como aponta (SASSERON \& CARVALHO, 2011)

\footnotetext{
Informações adicionais para relacionar D e C. Estas informações adicionais são, para Toulmin, as garantias (W), e nos permitem entender de que modo o argumento passou dos dados à conclusão. [...] as garantias podem ser regras ou princípios, mas não devem ser informações novas. São, portanto, afirmações gerais, hipotéticas; e são as garantias que nos permitem fazer o caminho dos dados às conclusões." (SASSERON \& CARVALHO, 2011, p. 101)
}

Evidenciado que, para além do simples ato de promover a argumentação, o Padrão de Toulmin ratifica o processo de aprendizagem, uma vez que, suas premissas partem de uma informação problemática e sem resposta, ao longo de seu processo de busca por respostas chega a conclusões, ou seja, o processo de argumentação é promovedor de inúmeras habilidades tais como identificar provas e dados, diferenciar atos e explicações, identificar e elaborar razões, formular explicações e conclusões, avaliar uma hipótese, justificar respostas, analisar criticamente, dar argumentos e contra argumentos, avaliar a consistência de sua coesão etc. (OLIVEIRA, 2017) 

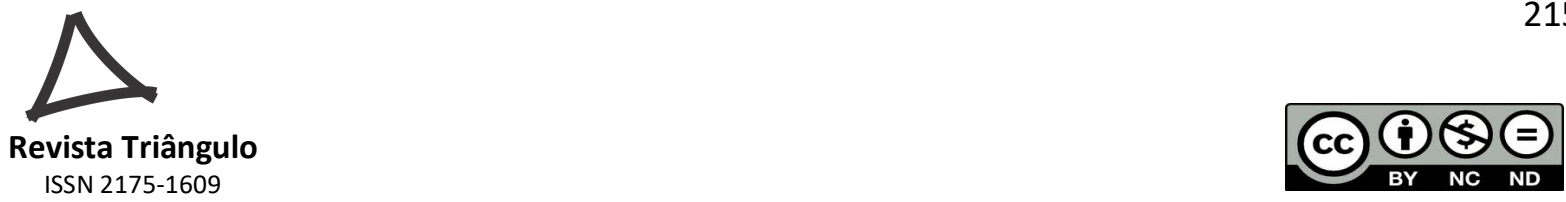

Portanto, de forma a afirmar que a grandeza da argumentação no ensino de ciências e de clamar por sua existência, como metodologia de ensino na sala de aula, afirmamos que a ação é também uma vertente promotora da exteriorização da aprendizagem que de antemão precisa ser alicerçada em parâmetros de diversidade e simbologia para o estudante. Motokane (2015) corrobora com essa afirmação da supremacia e amplitude da argumentação no processo de ensino nas aulas de ciências, ele afirma:

O desenvolvimento de habilidades argumentativas também promove a exteriorização da aprendizagem de um conteúdo ensinado quando os argumentos têm a chance de ser produzidos com base em argumentos científicos aprendidos em aula. Ao apresentarem seus argumentos, os alunos podem expressar como utilizam um determinado conceito científico para justificar uma opinião. Dessa forma, temos um indicador claro da aprendizagem do aluno. (MOTOKANE, 2015, p. 128-129)

Tendo em vista o propósito de que a educação científica, apresentamos o estudo realizado sobre o estado da arte das pesquisas que tratam da argumentação no ensino de Ciências no contexto nacional, dentro de uma perspectiva que pudesse evidenciar de fato como está composta a pesquisa sobre a argumentação no ensino de ciências e, para tanto, recorremos a uma análise salutar de especificidades ímpares que pudessem delinear este cenário.

\section{MATERIAIS E MÉTODO}

Este artigo teve sua construção inicial conduzida por ações de um levantamento bibliográfico, que buscou em três lócus específicos (periódicos, Encontros do ENPEC e a BDTD), fazendo uso do descritor Argumentação, a produção acadêmica de 2010 a 2018. Classificamos este trabalho como sendo um estado da arte ou estado do conhecimento que tem caráter bibliográfico, como salienta Ferreira (2006),

Definidas como de caráter bibliográfico, elas parecem trazer em comum o desafio de mapear e de discutir uma certa produção acadêmica em diferentes campos do conhecimento, tentando responder que aspectos e dimensões vêm sendo destacados e privilegiados em diferentes épocas e lugares, de que formas e em que condições têm sido produzidas certas dissertações de mestrado, teses de doutorado, publicações em periódicos e comunicações em anais de congressos e de seminários. Também são reconhecidas por realizarem uma metodologia de caráter inventariante e descritivo da produção acadêmica e científica sobre o tema que busca investigar, à luz de categorias e facetas que se caracterizam enquanto tais em cada trabalho e no conjunto deles, sob os quais o fenômeno passa a ser analisado. (FERREIRA, 2002, p. 258) 

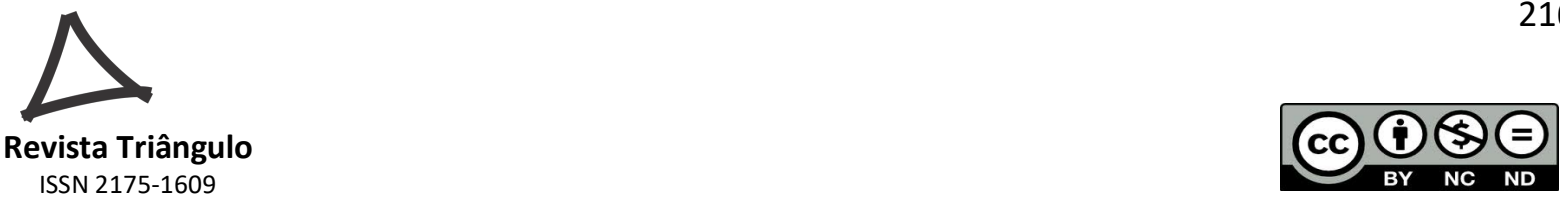

Vale salientar que na perspectiva de Fiorentini a ação de promover um levantamento bibliográfico se faz necessária com vistas a não produção de pesquisas com os mesmos vieses e objetivos. Fiorentini (1993), neste aspecto salienta que:

\begin{abstract}
Apenas uma pequena parcela (de educadores e pesquisadores) tem procurado verificar o que os colegas já investigaram a respeito de seu tema ou problema de pesquisa. Alguns justificam sua prática dizendo que os outros trabalhos não possuem o mesmo referencial teórico ou que não se inserem na mesma linha de pesquisa. Ora, não consultamos e citamos outros trabalhos apenas para lhes dar continuidade ou para buscar apoio às nossas ideias. Fazemos isso também para questionar ou até refutar seus pressupostos ou suas conclusões e encaminhamentos. (FIORENTINI, 1993, p. 56)
\end{abstract}

O levantamento bibliográfico a partir do descritor Argumentação no Ensino de Ciências foi realizado nos lócus que constam nas tabelas 1 (Periódicos), 4 (Encontros do ENPEC) e 5 (BDTD) e, a partir dos resultados desta pesquisa por este descritor, os trabalhos encontrados foram submetidos a uma leitura flutuante em busca de evidências e confirmações de que se tratava de uma pesquisa sobre a temática foco.

$\mathrm{Na}$ sequência, selecionamos os trabalhos que dialogavam sobre argumentação o que resultou em um montante, conforme consta na tabela 3. A construção deste mapeamento se deu a partir das pesquisas selecionadas e que constam como dito na tabela 3. Como primeira estratégia nos debruçamos sobre os aspectos e/ou itens: título, resumo e as palavras-chave para a constatação e ratificação de que os produtos analisados se referiam a temática do mapeamento; em seguida, optamos por construir gráficos com as informações obtidas da análise de modo a evidenciar e promover uma identificação e/ou constatação de características ímpares das pesquisas sobre Argumentação no Ensino de Ciências, sendo elas: Instituição de origem; Disciplina de trabalho da argumentação; Foco temático; Nível de escolaridade; Objetivo e/ou pretensão da pesquisa; Elemento de construção da argumentação ou ferramenta para sua análise; Autoria acadêmica e Resultados obtidos. A construção do estado da arte se fez salutar no processo de mapeamento que teve como objetivo: identificar e delinear como está configurada a produção acadêmica sobre a Argumentação no Ensino de Ciências. 


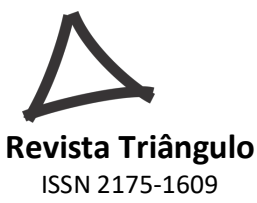

\section{ANÁLISE DOS DADOS E RESULTADOS}

O Estado da Arte obtido pelo levantamento bibliográfico a partir do descritor apresentado, anteriormente, nos revelou uma vasta produção para a Argumentação no Ensino de Ciências no Brasil para o período de 2010 a 2018. O produto deste levantamento resultou em 149 trabalhos/pesquisas, conforme a tabela 3, o que revela que a temática se apresenta com efetiva empregabilidade e contribuições para a educação e o processo de ensino.

Conforme descrevemos na tabela 1, para o período citado encontramos nas revistas eleitas 42 artigos, cuja dispersão no âmbito nacional foi ampla bem como a diversidade de seus vieses.

Tabela 1 - Periódicos analisados, quantidade de trabalhos localizados para o período de 2010 a 2018

\begin{tabular}{|c|c|}
\hline \multicolumn{1}{|c|}{ Tabela 1- Periódicos analisados, quantidade de trabalhos localizados para o período de 2010 a 2018 } \\
\hline Periódico & $\mathbf{N}^{\mathbf{0}}$ de trabalhos \\
\hline Revista Brasileira de Pesquisa em Educação em Ciências (RBPEC) & 04 \\
\hline Ciência \& Educação & 08 \\
\hline Investigações em Ensino de Ciências & 14 \\
\hline Ensaio: Pesquisa em Educação em Ciências & 08 \\
\hline Caderno Brasileiro de Ensino de Física & 06 \\
\hline Revista Química Nova & 02 \\
\hline
\end{tabular}

Fonte: Tabela criada pelos autores.

Na tabela 2, constam as descrições das revistas e/ou periódicos consultados para a busca de artigos, nela estão indicados o nome das revistas e o seu sítio na internet.

Levando em consideração que a Argumentação no Ensino de Ciências é uma temática já presente e com espaço no meio acadêmico, se faz necessário também buscar a existência de trabalhos produzidos nos cursos de pós-graduação, classificados como Dissertações e Teses, para tanto, a tabela 5 irá descrever o sítio de pesquisa da internet onde foi realizada a pesquisa para o item produção acadêmica.

Tabela 2: Revistas/Periódicos sítio na internet dos artigos consultados

\begin{tabular}{|c|c|}
\hline Revista/Periódico & Sítio na internet \\
\hline Rev. Brasileira, de Pesquisa em Ed. em Ciências (RBPEC) & https://seer.ufmg.br/index.php/rbpec \\
\hline Ciência \& Educação & http://www.scielo.br/cgi-bin/wxis.exe/iah/ \\
\hline Investigações em Ensino de Ciências & https://www.if.ufrgs.br/cref/ojs/index.php/ienci/index \\
\hline Ensaio: Pesquisa em Educação em Ciências & https://seer.ufmg.br/index.php/ensaio \\
\hline Caderno Brasileiro de Ensino de Física & https://periodicos.ufsc.br/index.php/fisica/index \\
\hline Revista Química Nova & http://www.scielo.br/scielo.php?script=sci serial\&pid=0100-042\&lng=pt\&nrm=iso \\
\hline
\end{tabular}

Na Tabela 3 apresentamos a síntese de produção dos trabalhos/pesquisas obtidos pela busca a partir do descritor: Argumentação, sendo esses, base e referencial para a análise que constitui o estado da arte produto do levantamento bibliográfico.

Tabela 3: Síntese dos trabalhos/pesquisas resultado da busca pelo descritor Argumentação

\begin{tabular}{|c|c|c|c|c|c|}
\hline \multicolumn{4}{|c|}{ Fonte de pesquisa } & \multicolumn{4}{|c|}{ Quantidade de trabalhos/pesquisas } \\
\hline Revistas/Periódicos & \multicolumn{4}{|c|}{ Set. / Dez. } & 2018 \\
\hline C Revista Triangulo & Uberaba, Minas Gerais & v.11 & n.3 p. 212-232 & Set. \\
\hline
\end{tabular}




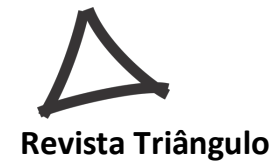

ISSN 2175-1609

\section{ENPECs}

Banco Digital de Teses e Dissertações - BDTD

Total de trabalhos/pesquisas obtidas

Fonte: Tabela criada pelos autores.

A Tabela 4 identifica os trabalhos apresentados nas edições dos ENPECs, dos anos de 2011, 2013, 2015 e 2017, também em ordem cronológica.

\begin{tabular}{|c|c|}
\hline Evento do ENPEC & Sítio na internet \\
\hline ENPEC 2011 - Campinas/SP & http://abrapecnet.org.br/atas enpec/viiienpec/trabalhos.htm \\
\hline ENPEC 2013 - Águas de Lindóia/SP & http://www.nutes.ufri.br/abrapec/ixenpec/atas/trabalhos.htm \\
\hline ENPEC 2015 - Águas de Lindóia/SP & http://www.abrapecnet.org.br/enpec/x-enpec/anais2015/trabalhos.htm \\
\hline ENPEC 2017 - Florianópolis/SC & http://www.abrapecnet.org.br/enpec/xi-enpec/anais/trabalhos.htm \\
\hline
\end{tabular}

Fonte: Tabela criada pelos autores.

De modo a ratificar com maior ênfase a amplitude de produção de pesquisas sobre a Argumentação no contexto nacional, realizamos também busca no Banco Digital de Dissertações e Teses (BDTD) tendo como preocupação, neste caso, não ocorrer a existência de pesquisas de mesma identidade entre as publicadas no BDTD e nos periódicos, uma vez que, é comum a publicação de artigos produtos de Teses e Dissertações.

Tabela 5 - Dissertações e Teses sobre tema argumentação no BDTD.

\begin{tabular}{|l|l|}
\hline \multicolumn{1}{|c|}{ Banco de Dissertações e Teses } & Sítio na internet \\
\hline BDTD- Biblioteca Digital Brasileira de Teses e Dissertações & http://bdtd.ibict.br/vufind/ \\
\hline Fonte: Tabela elaborada pelos autores com bases na revisão bibliográfica
\end{tabular}

Após a seleção dos materiais que constam na tabela 3, realizamos uma análise em busca das peculiaridades, sendo estas: ano de publicação; Instituição de Ensino Superior (IES) de origem; a produção e sua distribuição de acordo com os níveis de escolaridade; distribuição dos trabalhos de acordo com o foco temático; a presença do Padrão de Toulmin (2006) como Elemento de construção da argumentação e/ou ferramenta analítica; a produção autoral das pesquisas; os resultados das ações e/ou pesquisas realizadas nos trabalhos produzidos. Os resultados de ocorrências e identificações para esses "descritores" constam ao longo deste artigo na forma de gráficos.

\subsection{A quantidade de trabalhos e sua produção anual}

Tendo como base o levantamento bibliográfico realizado a partir do descritor argumentação que constam na tabela 3, constatamos uma amostra significativa da produção acadêmica nacional para essa temática no período de 2010 a 2018. Em síntese os dados nos revelam que houve expressiva produção e/ou publicação nos periódicos, no Encontro 
Nacional de Pesquisa em Educação em Ciências (ENPEC) e no Banco Digital de Teses e Dissertações cuja expressividade e comparação pode ser visualizada no gráfico 1.

De modo pontual e específico, se pode verificar uma maior produção em termos quantitativos para os anos de 2013 e 2017 para as publicações em revistas cientificas da área. Outro aspecto importante que se pode verificar com a análise do gráfico 1 é que poucos trabalhos foram publicados nas revistas e, um número expressivo nos ENPECs, já a produção acadêmica nos cursos de pós-graduação se apresenta relativamente alta. Vale apontar que os trabalhos que se encontram no ENPEC se tratam de pesquisas acadêmicas que dialogam tanto na vertente teórica quanto empírica, de modo que, o rol dos trabalhos garante uma fonte de dados privilegiada frente à produção com o viés do Ensino de Ciências e suas vertentes de práticas e metodologias de ensino que se fazem presentes nas práticas dos docentes e pesquisadores do nosso país e, dentro deste contexto, pode-se concluir que o interesse pela temática, Argumentação, tem crescido nos últimos anos e, as produções são visíveis nesse encontro, o qual se trata de um evento de expressão para a área do Ensino de Ciências.

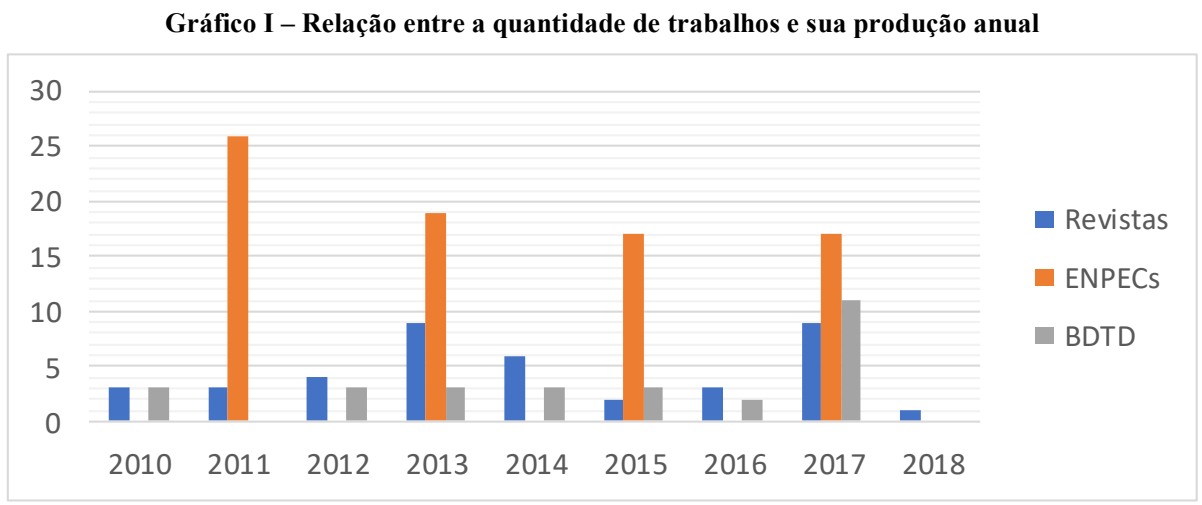

Fonte: Gráfico construído pelos autores.

A produção dos trabalhos nas revistas, nos ENPECs e no BDTD, conforme o gráfico 1, indica que no referido período de análise houve significativa produção. Se levarmos em consideração esse aspecto do mapeamento e relacioná-lo ao objetivo deste trabalho, que se refere a detalhar as pesquisas em Argumentação no Ensino de Ciências, de modo a caracterizar esta vertente da área acadêmica, cabe ainda especificar a instituição de origem e a área de concentração da Ciência a qual pretende este trabalho, com isso, pretendemos elucidar a produção científica sobre Argumentação em suas áreas da ciência da natureza, sendo elas: Biologia, Ciências, Física e Química. 


\subsection{A classificação dos trabalhos em suas áreas, níveis de escolaridade e instituições} de origem

A produção científica acadêmica em nosso país está dispersa nas inúmeras instituições de ensino. O levantamento a partir do descritor argumentação nas revistas foco deste mapeamento, bem como os trabalhos apresentados nos ENPECs e os que constam no BDTD, para o período estipulado, revelam que há uma grande dispersão de pesquisas deste caráter nas mais diversas instituições, bem como os dados nos revelam que a argumentação no ensino de ciências está presente em todas pequenas áreas (Biologia, Ciências, Química e Física) da grande área a Ciência da Natureza, bem como há distribuição relativa de trabalhos nos mais diversos níveis de escolaridade. O gráfico 2 revela a distribuição desses trabalhos e artigos para os elementos de classificação e a qual nível de escolaridade pertence, em contrapartida o gráfico 3 nos revela a classificação desses trabalhos quanto ao aspecto de inclusão e a qual área da ciência da natureza pertence.

Gráfico 2: Dispersão dos artigos e dos trabalhos pelo critério de classificação: nível de escolaridade.

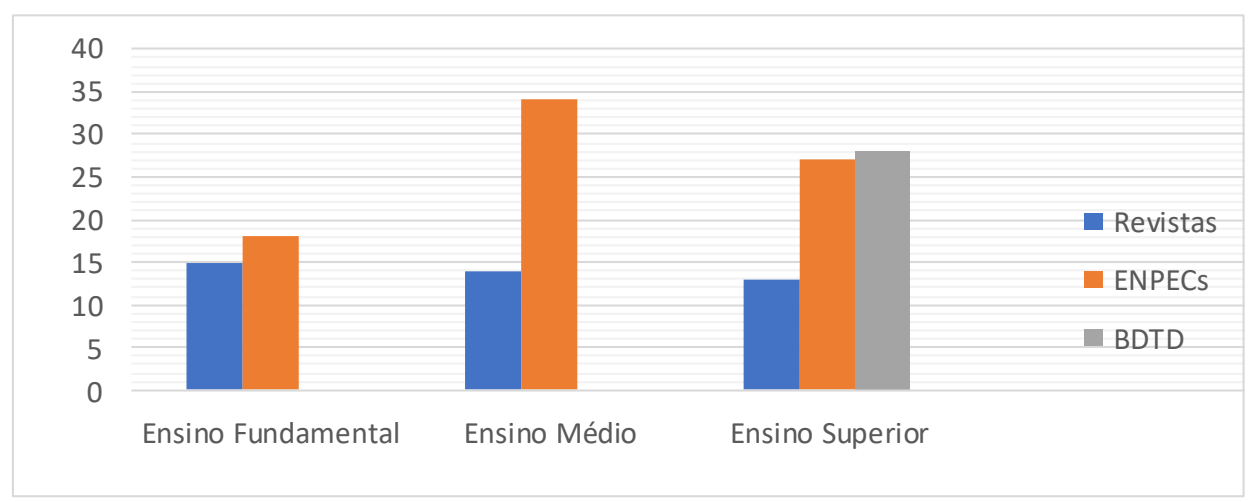

Fonte: Gráfico construído pelos autores a partir da revisão bibliográfica.

Os dados nos permitem dialogar sobre uma possível preferência de aplicação das pesquisas sobre Argumentação no Ensino de Ciências no Ensino Médio, isso se deve a existência de um maior número de disciplinas da área das Ciências da Natureza neste curso, sendo elas: Biologia, Física e Química. A segunda maior incidência de produção está no ensino superior dado o fato de que se trata das produções acadêmicas produzidas nos cursos de pós-graduação, mais especificamente nos cursos de Mestrado e Doutorado. 

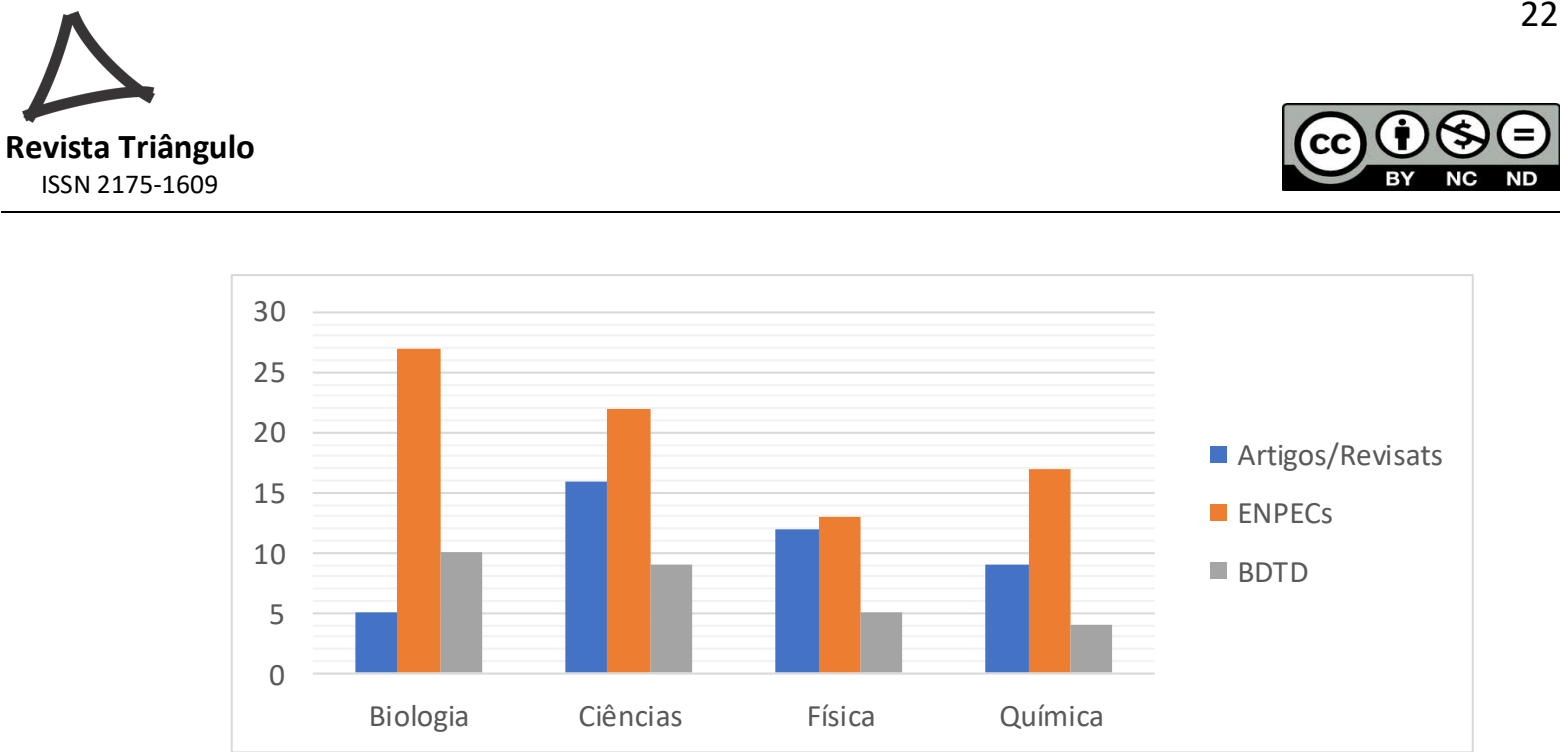

Fonte: Gráfico construído pelos autores a partir da revisão bibliográfica.

A análise dos dados do gráfico 3 evidencia que, no que se refere aos artigos publicados, há uma maior produtividade para a disciplina de ciências que está intrínseca ao ensino fundamental, ou seja, pode-se afirmar que para o período pesquisado houve grande aplicação de pesquisas publicadas em periódicos, tendo como base as aulas de ciências. Já nos ENPECs e no BDTD a efetiva produção está para a disciplina de Biologia, isso devido a sua amplitude e ramificação de áreas, já que encontramos trabalhos destinados à ecologia, à genética e às plantas. As pesquisas sobre a Argumentação têm sido realizadas em diversas Instituições de Ensino de nosso país, existindo maior incidência de produção na Universidade de São Paulo (USP) seguida da Universidade Federal de Minas Gerais (UFMG).

Gráfico 4: Distribuição dos trabalhos de acordo com as IES.

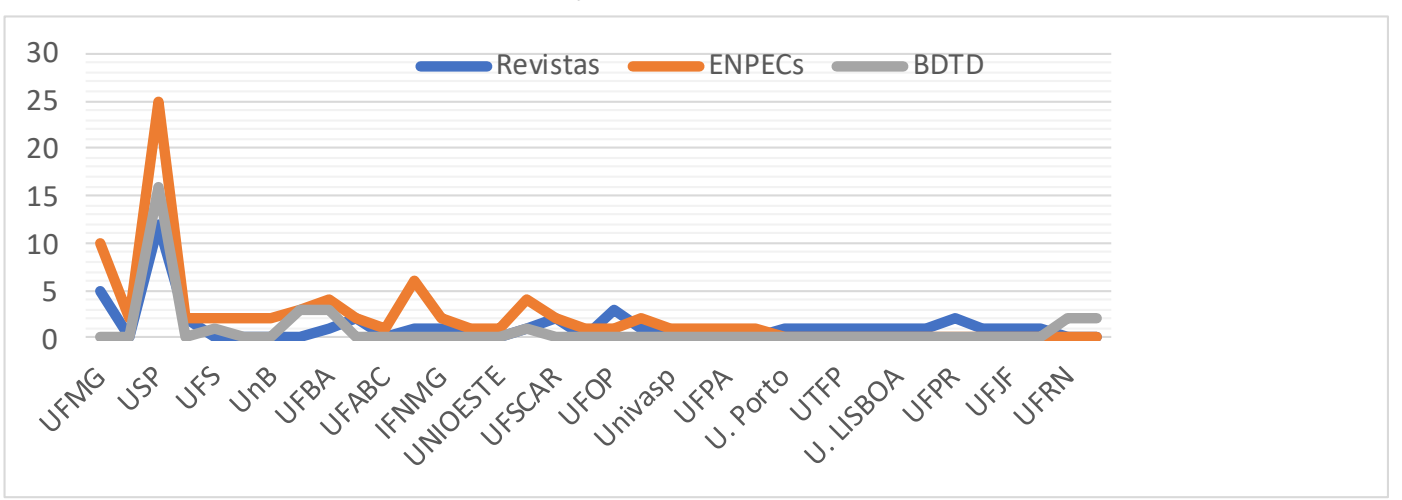

Fonte: Gráfico elaborado pelos autores a partir dos dados da revisão bibliográfica.

\subsection{O foco temático em que os trabalhos/pesquisas foram aplicados}

Ao analisarmos os artigos e os trabalhos pela leitura de seus resumos e considerações finais verificamos que, para o item foco temático, os trabalhos se distribuem em classificações específicas, de modo que há maior ênfase para pesquisas cujo viés está na promoção da argumentação científica, além disso, foram encontrados também, trabalhos e artigos que 

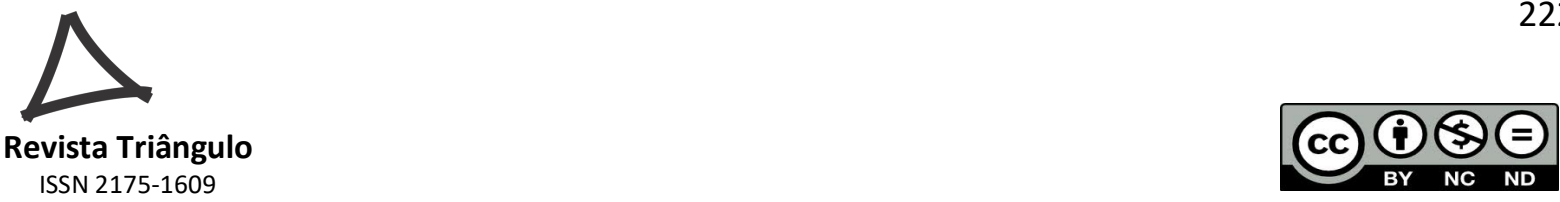

versam acerca da promoção da argumentação sociocientífica, da formação de docentes além de materiais que realizam um levantamento bibliográfico e ou resenhas de obras consagradas e que possuam, como foco central, a argumentação no ensino de ciências. O gráfico 5 nos revela o quadro da produção acadêmica brasileira sobre o foco temática da argumentação no ensino de ciências.

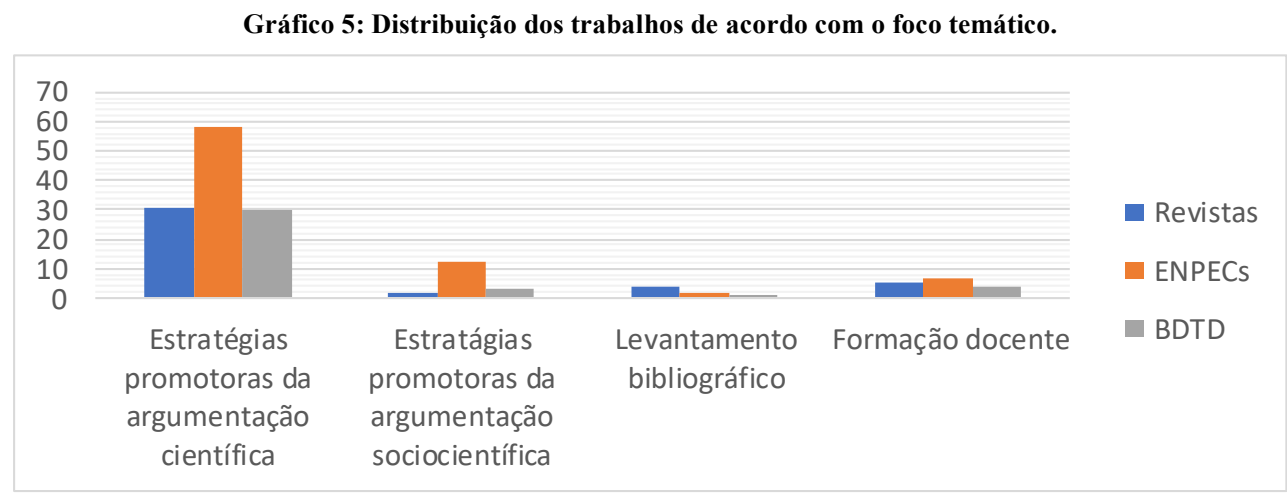

Fonte: Gráfico elaborado pelos autores a partir dos dados da revisão bibliográfica.

A análise dos trabalhos/pesquisas para a categoria foco temático revelou que as pesquisas se concentram em estratégias promotoras da construção da argumentação nos diversificadores de foco científico e sociocientífico, ou seja, os trabalhos dialogam sobre ações de promoção e construção da argumentação, fazendo uso ou não de questões sociais para o embasamento das discussões para a construção dos argumentos. Constatamos que, infelizmente, há um número baixo de trabalhos voltados para a formação docente sobre a argumentação, logo, salientamos sobre a importância do docente ao promover a educação pautada na argumentação, tenha suas ações conforme salienta a pesquisadora Anna Maria Pessoa de Carvalho (2013)

Para que este objetivo seja alcançado é necessário que o professor, por meio de pequenas questões, leve os alunos a: ponderar sobre o poder explicativo de cada afirmação, reconhecer afirmações contraditórias, identificar evidências e integrar diferentes afirmações mediante a ponderação de tais evidências (CARVALHO, 2013, p.31)

Vislumbramos na discussão deste foco temático, a salutar importância da diversidade de estratégias para a construção da argumentação, salientando que cabe ao docente estar em constante formação. 


\subsection{Os objetivos/pretensões dos trabalhos tendo como propósito a argumentação no} ensino de Ciências

A temática Argumentação no Ensino de Ciências tem apresentado crescimento em sua produção acadêmica, neste sentido, cabe a indagação e a constatação de qual é o objetivo e/ou a pretensão das pesquisas realizadas para este tema. O gráfico 6 nos revela o panorama dessa distribuição que apresenta a diversidade de objetivos/pretensões, sendo elas: 1-Construir, desenvolver e incentivar a argumentação científica; 2- Analisar a argumentação científica; 3Investigar questões relativas a argumentação; 4- Constatar a qualidade, bem como avaliar os dos argumentos produzidos frente a estratégias específicas; 5- Identificar a argumentação pela prática discursiva; 6- Promover a argumentação para a Alfabetização científica e 7- Promover a argumentação pela experimentação.

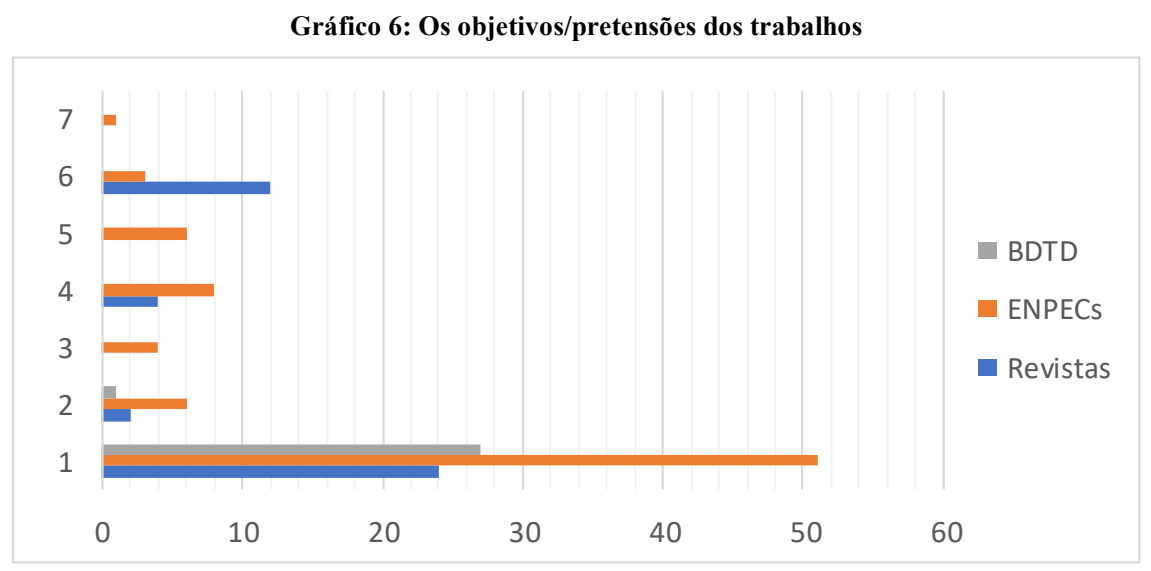

Fonte: Gráfico elaborado pelos autores a partir dos dados da revisão bibliográfica.

A análise dos dados nos confere amplitude de identificação das pesquisas realizadas em nosso país, constatamos que a maior incidência e/ou existência das pesquisas está para ações de verificação da elaboração, do ato de instigar e/ou estimular e, de posse da produção das argumentações dos alunos e/ou dos licenciandos, a análise da qualidade dessas argumentações estando, essa ação, pautada em modelos e/ou Padrões conhecidos da área acadêmica, como promovedor e ou verificador de um argumento científico de expressão.

\subsection{O elemento constitutivo/ferramenta analítica da argumentação}

As pesquisas sobre Argumentação no Ensino de Ciências recorrem a referenciais teóricos que discutem e abordam a temática com base em padrões, mecanismos de promoção e/ou meios para se promover, analisar, constatar, construir e identificar a qualidade da 


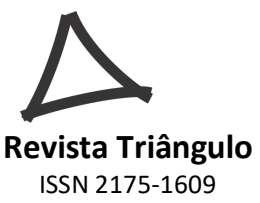

argumentação. Como resultado, da análise das produções analisadas, verificamos que existe um Padrão de maior ênfase nos trabalhos, no entanto, para além dele, encontramos outros que regem os trabalhos singularmente ou em conjunto. Assim, para as pesquisas em Argumentação no Ensino de Ciências, encontramos o TAP, Padrão de Toulmin, conforme consta na figura 1.

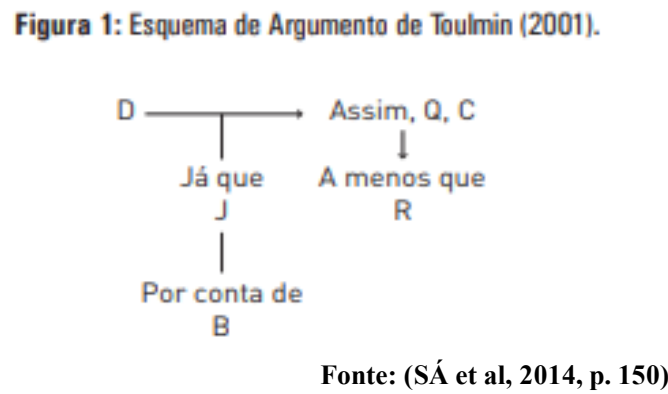

E que apresenta especificidades e de fato um padrão a ser seguido, como nos aponta SÁ et al 2014.

Segundo Toulmin (2001), os elementos fundamentais de um argumento são o dado (D), a conclusão (C) e a justificativa (J). É possível apresentar um D Já que J A menos que R Assim, Q, C Por conta de B Esquema de argumento de Toulmin como instrumento de ensino: explorando possibilidades Revista argumento contando apenas com esses elementos, cuja estrutura básica é: "a partir de um dado D, já que J, então C". Porém, para que um argumento seja completo, pode-se especificar em que condições a justificativa apresentada é válida ou não, indicando um peso para tal justificativa. Dessa forma podem ser acrescentados ao argumento qualificadores modais (Q), ou seja, especificações das condições necessárias para que uma dada justificativa seja válida. Da mesma forma, é possível especificar em que condições a justificativa não é válida ou suficiente para dar suporte à conclusão. Nesse caso é apresentada uma refutação (R) da justificativa. (SÁ et al, 2014, p. $150-151)$

Nesse caso, estamos nos referindo ao elemento de construção da argumentação, bem como das ferramentas analíticas da existência e da qualidade da argumentação. O gráfico 7 nos revela os dados encontrados em nossa análise e, como dito, trataremos neste gráfico apenas da identificação do Padrão de Toulmin e usaremos para os demais a classificação em um subgrupo que dominaremos de: Demais padrões, que terão suas especificidades descritas em seguida. 

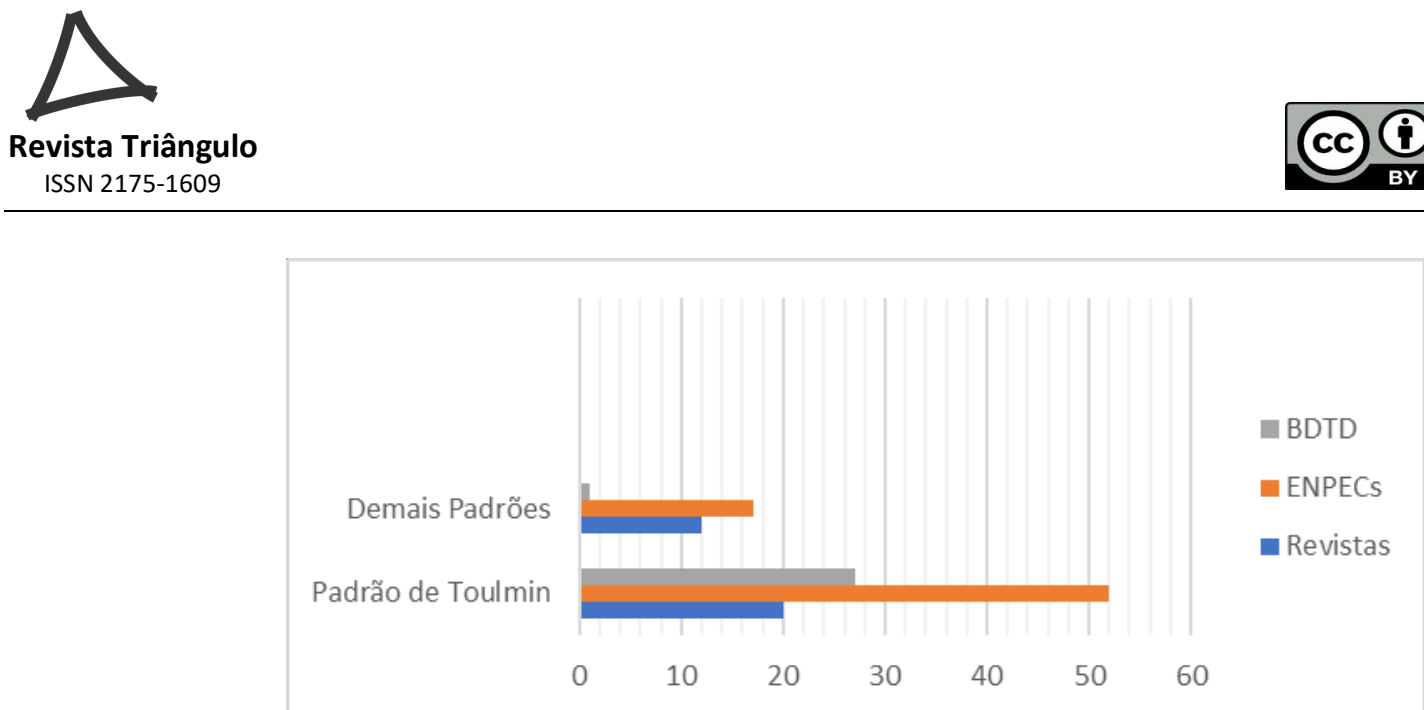

Fonte: Gráfico elaborado pelos autores a partir dos dados da revisão bibliográfica.

Foi relativamente importante vislumbrar que as pesquisas em Argumentação não estão apenas atreladas a um único elemento de construção e/ou ferramenta analítica, no caso tínhamos a hipótese de que apenas o Padrão de Toulmin fosse o único em prática, mas, satisfatoriamente, encontramos outros padrões, o que nos mostra que as pesquisas buscam por outros mecanismos, por identificarem que há diversidade de possibilidades de que a argumentação seja e esteja mais acessível nas escolas. Dentre os outros padrões e ou ferramentas de análise para a Argumentação no Ensino de Ciências, destacamos e elucidamos alguns dos que encontramos em nossa análise de modo a especificá-los, são eles: Pragma Dialética; Quadro analítico de Raimbow; Lawson; Berland \& McNeil; Lógica Filosófica; SIMON; ERDURAN; OSBORNE; Ducrot; Kelly \& Takao; os Procedimentos Discursivos Didáticos (PDD), dentre outros. Para tais ferramentas realizamos alguns apontamentos a seguir:

A estratégia identificada como Pragma Dialética é uma ferramenta utilizada para a argumentação que tem o propósito de ação para melhor compreender o seu processo nas práticas educativas, conforme o diálogo de SOUTO et al (2011)

Para os autores da teoria Pragma-dialética, a "Estrutura da Argumentação" refere-se à relação entre um ponto de vista e seus argumentos. Esses são elementos utilizados para apoiar ou refutar um ponto de vista. No presente estudo, utilizamos a expressão "Situação argumentativa" para indicar o conjunto de pontos de vista e seus argumentos envolvidos no processo de resolver diferenças de opinião subordinadas e principal relacionadas a um mesmo tema. Além disso, quando utilizamos a expressão "processo da argumentação" estamos nos referindo às interações entre os participantes e às formas como o professor usa a linguagem durante as situações. (SOUTO et al, 2011, p. 4)

O Quadro analítico de Rainbow se caracteriza por ser uma ferramenta analítica que tem como propósito verificar os debates e as discussões de uma argumentação, pautando-se em sete categorias: Categoria 1: Interações que não se relacionam de modo algum com a 
tarefa prescrita pelo professor; Categoria 2: Comentários que se relacionam a aspectos sociais; Categoria 3: Comentários e interações que se relacionam à comunicação, como confirmação de presença, ou de entendimento das diretrizes fornecidas no ambiente virtual; Categoria 4: Comentários e interações que se relacionam à organização da tarefa; Categoria 5: Afirmações relacionadas à opinião dos alunos; Categoria 6: Todos os argumentos e contra-argumentos usados pelos alunos para apoiar ou refutar uma afirmação; Categoria 7: Todos os comentários que exploram e aprofundam os contra-argumentos. (QUEIROZ \& SOUZA, 2013)

O Padrão de Lawson na perspectiva de Sasseron \& Carvalho (2011) é outro padrão para a verificação e constatação do processo de construção do argumento, ele recorre a um raciocínio hipotético-dedutivo. Este processo se resume conforme o descrito por

\begin{abstract}
Segundo Lawson, etapas recorrentes no pensar cientificamente envolvem: 1) observação de um fenômeno que gere interesse pela 2) proposição de um mecanismo causal capaz de explicá-lo (formulação de uma hipótese ou explicação); 3) previsão sobre o comportamento do fenômeno mediante a causa hipotetizada usando o conhecimento prévio como garantia (condições de base) para os resultados esperados; 4) teste da hipótese observando os efeitos reais decorrentes da causa proposta e comparando-os com os efeitos esperados; e 5) conclusão sobre a validade da hipótese formulada. (FREIRE \& MOTOKANE, 2013)
\end{abstract}

O Padrão de Berland \& McNeil, em linhas gerais, faz uso de categorias para o processo argumentativo, pautando-se em seus respectivos graus de complexidade, sendo eles distribuídos em quatro categorias. Especificamente as categorias e a descrição dos graus de complexidade são: 1: Afirmação e justificação de suas próprias conclusões; 2: Questionamento das conclusões uns dos outros; 3: Avaliação de suas próprias conclusões e de seus pares; 4: Reelaboração de suas próprias conclusões e de seus pares. (VALLE \& MOTOKANE, 2013)

A Lógica Filosófica descreve um argumento como uma sequência de enunciados ou proposições que compreendem ideais e significados, expressos em sentenças declarativas. (QUADROS \& CUNHA,2015, p. 3)

Para os pesquisadores Simon; Erduran; Osborne (2006): seu instrumento analítico tem o objetivo de facilitar a argumentação em sala de aula que se resumem em categorias e códigos pró-argumentação, sendo essas oito categorias que devem estar em consonância de ação de declarações/afirmações/solicitações dos professores para desencadeamento dos processos argumentativos, assim são essas categorias e ações, conforme descritas na tabela 6 . 

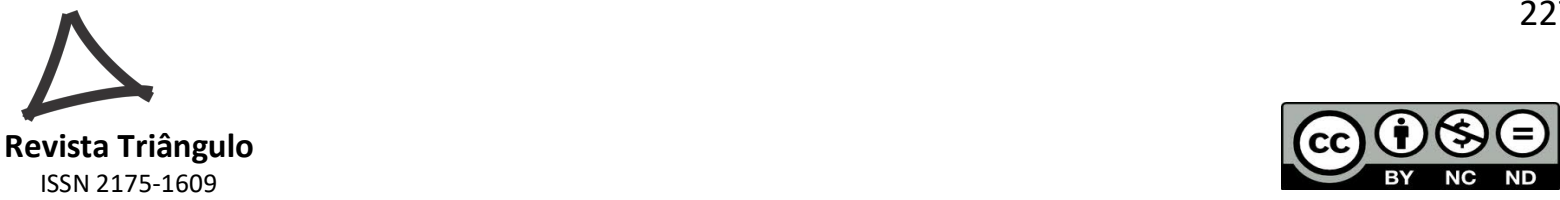

\begin{tabular}{|l|l|}
\hline \multicolumn{1}{|l}{ Tabela 6: Categorias e códigos pró- argumentação segundo Simon, Erduran e Osborne (2006). } \\
\hline CATEGORIAS & $\begin{array}{c}\text { Declarações/afirmações/solicitações dos professores para desencadeamento dos processos } \\
\text { argumentativos }\end{array}$ \\
\hline Falar e ouvir & Incentiva a discussão entre os alunos \\
\hline Conhecer o significado do argumento & Define e exemplifica o argumento \\
\hline Posicionar-se na construção dos argumentos & $\begin{array}{l}\text { Encoraja as ideias dos alunos; incentiva a escolha de explicações; valoriza diferentes } \\
\text { pontos de vista }\end{array}$ \\
\hline Justificar com evidências & $\begin{array}{l}\text { Verifica a existência de dados para sustentar os argumentos; fornece dados; } \\
\text { Solicita/Enfatiza justificativas; Estimula o conflito de ideias }\end{array}$ \\
\hline Construir argumentos & Solicita que os alunos apresentem seus argumentos na forma escrita e/ou oral \\
\hline Avaliar os argumentos & Incentiva a avaliação dos argumentos e de seus componentes pelos alunos \\
\hline Contra-argumentar/ Debater & Incentiva a contra argumentação durante a construção dos argumentos e debate \\
\hline Refletir sobre o processo de discussão & $\begin{array}{l}\text { Estimula a reflexão dos processos adotados pelos alunos para a construção do argumento e } \\
\text { para convencer os demais a mudarem de opinião }\end{array}$ \\
\hline
\end{tabular}

O Padrão de Ducrot se baseia na esfera da verificação da enunciação, ou seja, muitos atos de enunciação têm função argumentativa:

Essa função tem marcas na própria estrutura do enunciado: o valor argumentativo de uma frase não é somente uma consequência das informações por ela trazidas, mas a frase pode comportar diversos morfemas, expressões de termos que, além de seu conteúdo informativo, servem para dar uma orientação argumentativa ao enunciado, a conduzir o destinatário em tal ou qual direção. (DUCROT, 1981, p. 178)

Kelly e Takao apresentam um modelo de argumentação e, partem do princípio de que o Modelo de Argumentação de Toulmin, que é usualmente utilizado pelos pesquisadores para a argumentação nas aulas de ciências, baseia-se na reflexão estrutural do argumento de forma a elucidar e tornar evidente os seus componentes salientando, ao máximo, as suas relações lógicas que se encontram em caracterizados por níveis epistêmicos, conforme descrito na tabela 7.

Tabela 7: Níveis epistêmicos de Kelly e Takao.

\begin{tabular}{|l|l|}
\hline Níveis & \multicolumn{1}{c|}{ Definição } \\
\hline I & Proposições que fazem referência explícita à representação de dados (em gráficos, tabelas etc). \\
\hline II & $\begin{array}{l}\text { Proposições que identificam e descrevem propriedades e características topográficas da estrutura geológica específica da área } \\
\text { geográfica em estudo. }\end{array}$ \\
\hline III & Proposições que descrevem relações entre as estruturas geológicas específicas da área geográfica em estudo. \\
\hline IV & $\begin{array}{l}\text { Proposições apresentadas na forma de assertivas teóricas ou de modelos que são ilustrados com dados específicos da área } \\
\text { geográfica em estudo. }\end{array}$ \\
\hline V & Proposições apresentadas na forma de assertivas teóricas ou de modelos específicos para a área geográfica em estudo. \\
\hline VI & $\begin{array}{l}\text { Proposições gerais que reportam processos geológicos e fazem referência a definições usualmente presentes em livros-texto. } \\
\text { O conhecimento apresentado pode ser mais amplo, não apenas relacionado à área geográfica em estudo. }\end{array}$ \\
\hline
\end{tabular}

Fonte: OLIVEIRA et al, 2010, p. 1982

Os Procedimentos Discursivos Didáticos (PDD) se caracterizam por ser um modelo e/ou padrão que se baseia em ações que se constituem nos meios pelos quais o professor gerencia e conduz o discurso de sala de aula. Para esta prática se coloca como gerenciador da argumentação a partir dos PDD. Na perspectiva de VIEIRA et al, 2014, p. 298 “Os procedimentos satisfazem o critério de racionalidade, evidenciado pelo seu caráter argumentativo, que passaremos a demonstrar a partir de análises discursivas de um trecho de episódio argumentativo de quatro minutos de duração".

\begin{tabular}{l|c|c|c|c|c} 
(C) Revista Triangulo & Uberaba, Minas Gerais & v.11 & n.3 p. 212-232 & Set. / Dez. & 2018
\end{tabular}




\subsection{A produção autoral das pesquisas}

A prática da realização de pesquisas acadêmicas em nosso país tem apresentado relativo crescimento nas últimas décadas e, para a temática a Argumentação no Ensino de Ciências essa afirmação é compartilhada. Quando se trata da produção acadêmica apresenta, tendenciosamente, uma acentuada produção para determinados pesquisadores, mas isso se deve ao fato desses estarem ligados ou pertencerem a linhas de pesquisas exclusivas, bem como serem integrantes de grupos de pesquisas cujas discussões fomentam a produção acadêmica.

Para a temática a Argumentação no Ensino de Ciências, o nosso mapeamento demonstrou que existe um maior número de produção de trabalhos publicados em revistas e/ou nos ENPECs e, há um crescente interesse de outros pesquisadores desenvolvendo trabalhos de expressão nesta linha de pesquisa. Apresentamos no gráfico 8 a distribuição autoral, dos catorze autores/pesquisadores elencados numericamente como: 1- Danusa Munford; 2- Lúcia Helena Sasseron; 3- Rodrigo Drumond Vieira; 4- Salete Linhares Queiroz; 5- Rosária Justi; 6- Marcelo Tadeu Motokone; 7- Sílvia L. F. Trivelato; 8- Mírian Rejane M. Mendes; 9- Wildosn L. P. Santos; 10- Stefannie de S. Ibraim; 11- Daniela Scarpa; 12- Silvia Regina Q. A. Zuliani; 13- Maria Gorette Lima da Silva; 14- Francimar Martins T. Macedo. Salientamos que apontamos a autoria identificada daqueles que possuem mais de um trabalho seja publicado no formato de artigo em revistas ou periódicos e nos ENPECs; Aqueles que após a análise apresentaram apenas uma publicação não constam no gráfico e, de modo a compor a totalidade de publicações analisadas, salientamos que existem ainda outros 12 autores com publicação em revistas/artigos e 44 autores com trabalhos apresentados nos ENPECs. 

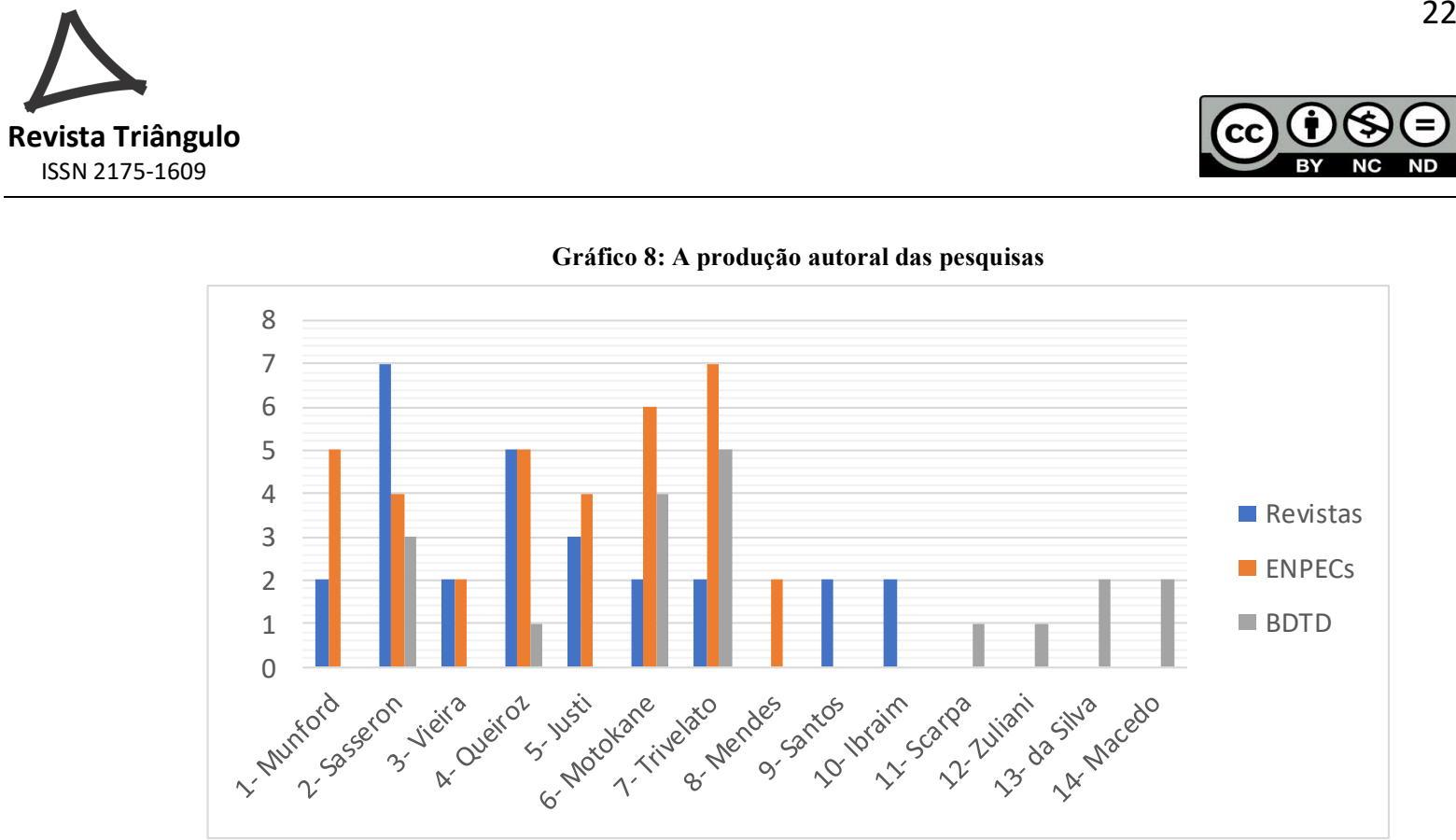

Fonte: Gráfico construído pelos autores a partir dos dados da revisão bibliográfica

\subsection{Os resultados das pesquisas publicadas de 2010 a 2018}

Um dos itens de maior viabilidade para este mapeamento é a identificação dos resultados obtidos com as pesquisas realizadas para a Argumentação Científica, satisfatoriamente, nos deparamos com uma grande diversidade de resultados. Tal diversidade expressa que a Argumentação Científica está para além de uma vertente simples de favorecimento para as práticas de ensino e, acima de tudo para com a aprendizagem das ciências, de um modo geral. No gráfico 9, apresentamos a distribuição desses resultados, em números e, salientamos que a diversidade está na aquisição, desenvolvimento ou constatação de: Resultado 1- Diferentes estratégias são promotoras da Argumentação de qualidade; Resultado 2- Práticas efetivas de desenvolvimento de argumentação em licenciandos; Resultado 3- As discussões Sociocientíficas favorecem o desenvolvimento da argumentação; Resultado 4- Atividades investigativas favorecem a argumentação; Resultado 5- Atividades de experimentação favorecem a argumentação; Resultado 6- Atividades discursivas favorecem a argumentação; Resultado 7- O Padrão de Toulmim é eficiente para a argumentação; Resultado 8- A argumentação desenvolve o conhecimento científico; Resultado 9- As práticas de Júri Simulado desenvolvem a argumentação; Resultado 10- O estímulo ao levantamento de hipóteses favorece a argumentação; Resultado 11- A Argumentação é elemento promotor da Alfabetização Científica; Resultado 12- É preciso estimular a argumentação dos alunos; Resultado 13- A modelagem favorece a argumentação; Resultado 14- Argumentação gera Autonomia e Raciocínio; Resultado 15- Os argumentos são melhores construídos coletivamente; Resultado 16- A discussão de elementos forense 
favorece a argumentação; Resultado 17- O uso de Argument-Driven-Inquery é efetivo; Resultado 18- Os mapas conceituais favorecem a construção da argumentação; Resultado 19A argumentação dos alunos é apenas composta por justificativa.

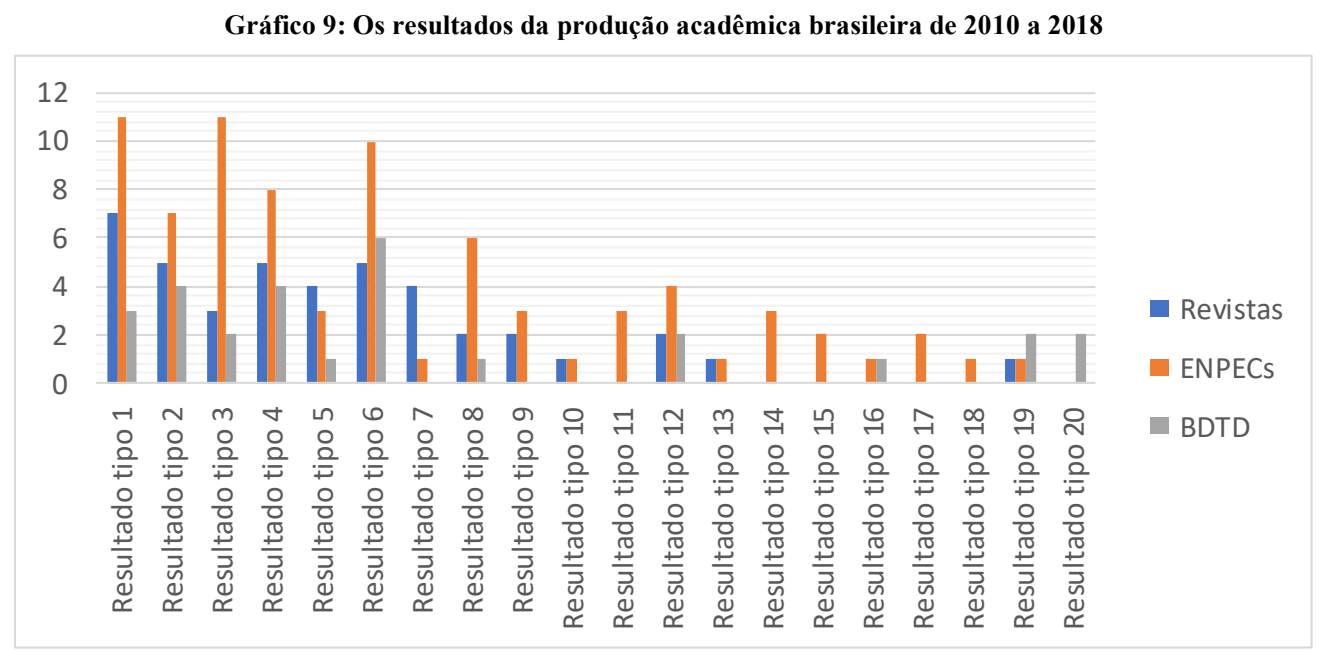

Fonte: Gráfico construído pelos autores a partir dos dados da revisão bibliográfica

Fica evidente que a argumentação no ensino de ciências se constitui em uma ação diversificada e que, acima de tudo, devemos defender a sua existência na sala de aula de forma efetiva, e neste contexto cabe com urgência a formação docente que confira aos mesmos subsídios para a realização dessas práticas que, conforme mostram os resultados das pesquisas analisadas para este artigo, a argumentação se faz possibilitadora, de fato da alfabetização científica e do conhecimento científico e está para além desses elementos, por se fazer constituidora de inúmeras habilidades e competências necessárias para a formação do cidadão.

\section{CONSIDERAÇÕES FINAIS}

O estudo nos revela que a argumentação no ensino de ciências é uma temática de grande importância para a comunidade científica, dado o montante de pesquisas produzidas e pelas discussões que os trabalhos/artigos e pesquisas fomentam, uma vez que, as pesquisas não se mostraram rotineiras e de frequência constante, mas sim, há um rol de diversidade de objetivos, ações e resultados obtidos a partir das práticas da argumentação científica em sala de aula. Em linhas gerais as pesquisas estão distribuídas também entre as IES, para as disciplinas de foco da ciência da natureza e para as questões e vieses científicos e sociocientíficos. 


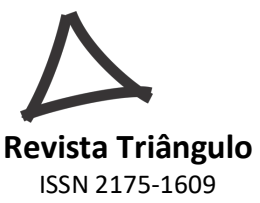

É de salutar importância identificarmos, nas pesquisas sobre a argumentação científica, estratégias promotoras da argumentação sociocientífica, uma vez que se faz urgente a formação cidadã frente a essas questões e, apontarmos que os resultados mostraram que, a quando se atua a partir dessas questões, a argumentação fora desenvolvida com qualidade, além de promoverem o desenvolvimento da habilidade argumentativa, que certamente propicia o desenvolvimento no processo de tomada de decisões e no favorecimento do conhecimento científico.

Identificamos, também, uma produção substancial frente a pesquisas que atuam na construção da argumentação, apesar de que os modelos são tendenciosos, o que nos remete a necessidade de pesquisas que possam diversificar esse processo.

No que se refere a trabalhos que se pautem no viés das premissas dos elementos de construção da argumentação utilizados por Toulmin, identificamos que esse continua sendo o Padrão mais efetivo, com inserção de outros modelos para a análise da argumentação construída, dadas as especificidades desse método, padrão que se preocupa em promover e estabelecer a partir de uma estrutura composta por um dado que pode levar a conclusão se houver uma garantia por meio do conhecimento, ou não conclusão por meio de ou viés oposto que refuta o dado, esta estrutura leva segundo Toulmin (2006) a viabilidade ou não do argumento.

\section{REFERÊNCIAS}

DUCROT. O. Provar e dizer. São Paulo: Global, 1981.

FERRAZ, A. T.; SASSERON, L. H. Propósitos epistêmicos para a promoção da argumentação em aulas investigativas. Investigações em Ensino de Ciências, v. 22, n. 1, 2017.

FERREIRA, J. Q.; DE ABREU FERREIRA, L. N.; QUEIROZ, S. L. Argumentação na formação inicial de professores de química. In: Encontro Nacional de Pesquisa em Educação em Ciências, 10, 2015, Águas de Lindóia/SP.

FERREIRA, N. S. de A. As pesquisas denominadas 'estado da arte'. Educação \& Sociedade, ano 23, p. 257-272, ago. 2002.

FIORENTINI, D. Memória e análise da pesquisa acadêmica em Educação Matemática no Brasil: o banco de teses do CEMPEM/FE-Unicamp. Zetetiké, v 1, n.1, p.55-76, mar. 1993.

FREIRE, C.C.; MOTOKANE, M. T. O uso do raciocínio hipotético dedutivo para promover a argumentação na formação continuada de professores de biologia. In: Encontro Nacional de Pesquisa em Educação em Ciências, 9, 2013, Águas de Lindóia/SP. 


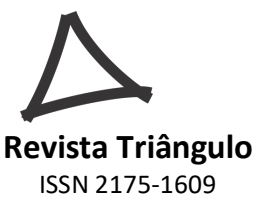

KUHN, D. Science Argumentation: implications for teaching and learning scientific thinking. Science Education, v. 7, n. 3, p. 319-337, 1993.

MOTOKANE, M. T. Sequência didáticas investigativas e argumentação no ensino de ecologia. Ensaio. v. 17, n. especial, p. 115-137. 2015

OLIVEIRA, Jane Raquel Silva de et al. Escrita científica de alunos de graduação em química: análise de relatórios de laboratório. Química Nova, v. 33, n. 9, p. 1980-1986, 2010.

OLIVEIRA, T. L. S. Influência dos Propósitos Epistêmicos e das Ações Típicas do professor na promoção da argumentação em aula investigativa de Ciências. $2016.83 \mathrm{f}$. Dissertação de Mestrado - Universidade de São Paulo, São Paulo, 2016.

QUADROS MARQUES, G.; CUNHA, M. B. A argumentação escrita de estudantes do ensino médio de uma escola de Toledo/PR sobre fenômenos químicos. In: Encontro Nacional de Pesquisa em Educação em Ciências, 10, 2015, Águas de Lindóia/SP.

QUEIROZ, S.; SOUZA, N. Argumentação colaborativa no ensino de química: uso do quadro analítico rainbow na avaliação do aprofundamento e da extensão. Enseñanza de las ciencias, n. Extra, p. 2871-2877, 2013.

SÁ, L. P.; QUEIROZ, S. L. Argumentação no ensino de ciências: contexto brasileiro. Ensaio Pesquisa em Educação em Ciências (Belo Horizonte), Belo Horizonte, v. 13, n. 2, p. 13-30, Aug. 2011.

SÁ, L. P.; KASSEBOEHMER, A. C.; QUEIROZ, S. L. Esquema de argumento de Toulmin como instrumento de ensino: explorando possibilidades. Ensaio Pesquisa em Educação em Ciências, v. 16, n. 3, p. 147-170, 2014.

SASSERON, L. H.; CARVALHO, A. M. P. Construindo argumentação na sala de aula: a presença do ciclo argumentativo, os indicadores de alfabetização científica e o padrão de Toulmin. Ciência \& Educação, v. 17, n. 1, p. 97-114, 2011.

SIMON, S.; ERDURAN, S.; OSBORNE, J. Learning to teach argumentation: Research and development in the science classroom. International Journal of Science Education, v. 28, n. 2-3, p. 235-260, 2006.

SOUTO, A. P. S; SILVA, D. O.; MUNFORD, D. Argumentação no ensino de conceitos da biologia: práticas de um professor de ciências em salas de aula da EJA. ENCONTRO NACIONAL DE EDUCAÇÃO EM CIÊNCIAS, v. 8, 2011.

VALlE, M. G.; MOTOKANE, M. T. Processo argumentativo em aulas de ecologia. In: Encontro Nacional de Pesquisa em Educação em Ciências, 9, 2013, Águas de Lindóia/SP.

VIEIRA, R. D.; DE MELO, V. F.; DA ROCHA BERNARDO, J.R. Os Procedimentos Discursivos Didáticos como saberes experienciais exemplares de um formador de professores de física. Caderno Brasileiro de Ensino de Física, v. 31, n. 2, p. 289-305, 20 